\title{
Exploratory study of mesopore templating with carbon during zeolite synthesis
}

\author{
A.H. Janssen ${ }^{\text {a }}$, I. Schmidt ${ }^{\text {b }}$, C.J.H. Jacobsen ${ }^{\text {b }}$, A.J. Koster ${ }^{\text {c }}$, K.P. de Jong ${ }^{\text {a,* }}$ \\ a Department of Inorganic Chemistry and Catalysis, Debye Institute, Utrecht University, P.O. Box 80 083, Sorbonnelaan 16, 3584 CA, \\ Utrecht, The Netherlands \\ ${ }^{\mathrm{b}}$ Haldor Topsøe A/S, Nymollevej 55, DK-2800 Lyngby, Denmark \\ ${ }^{\mathrm{c}}$ Department of Molecular Cellbiology, Utrecht University, Padualaan 8, 3584 CH, Utrecht, The Netherlands
}

Received 8 March 2003; received in revised form 11 July 2003; accepted 26 July 2003

\begin{abstract}
Here we present an exploratory study on the generation of mesopores in zeolite crystals by templating with carbon during synthesis. With nitrogen physisorption, scanning electron microscopy and (three-dimensional) transmission electron microscopy we have studied the influence of the carbon source and zeolite synthesis conditions on the mesopores generated after the carbon has been burned off. In particular, silicalite-1 crystals have been synthesized in the presence of a carbon matrix. After burning off the carbon, zeolite samples with mesopore volumes between 0.05 and $0.71 \mathrm{ml} / \mathrm{g}$ were obtained. With dissolved $\mathrm{SiO}_{2}$ at a crystallization temperature of $150{ }^{\circ} \mathrm{C}$ large crystals $(15 \mu \mathrm{m}$ length $)$ were obtained, whereas the use of tetraethylorthosilicate at a crystallization temperature of $170{ }^{\circ} \mathrm{C}$ yielded crystals with a size between 0.5 and $6 \mu \mathrm{m}$. Low heating rates $\left(0.5^{\circ} \mathrm{C} / \mathrm{min}\right)$ to a final crystallization temperature of $170{ }^{\circ} \mathrm{C}$ led to rather uniform small zeolite crystals $(0.6-1 \mu \mathrm{m})$, whereas the crystals were less uniform in size when the autoclave was rapidly heated to the final temperature, i.e. also much larger crystals were found. Both carbon nanofibers and carbon black aggregates were capable to act as a template for cylindrical mesopores that start at the external surface of the zeolite crystals. However, the tortuosity of the mesopores templated by the carbon black aggregates was much higher than the cylindrical mesopores templated by the carbon nanofibers. With increasing zeolite crystal size the chance that carbon aggregates are completely surrounded by the zeolite increases, leading to inkbottle type mesopores. The results show for the first time carbon nanofiber skeins to be highly promising secondary templates to obtain cylindrical mesopores with a low tortuosity in zeolite crystals.
\end{abstract}

(c) 2003 Elsevier Inc. All rights reserved.

Keywords: Zeolites; Mesopores; Template; Synthesis; Carbon

\footnotetext{
${ }^{*}$ Corresponding author. Tel.: +31-30-2536-762; fax: +31-302511-027.

E-mail address: k.p.dejong@chem.uu.nl (K.P. de Jong).
}

\section{Introduction}

Zeolites with hierarchical porous structures combining micropores with mesopores and/or macropores are attractive for a wide range of applications such as catalysis, adsorption and separation [1-5]. In order to create a zeolite with a 
hierarchical pore structure roughly three approaches can be followed. The first is to support small zeolite crystals on e.g. latex spheres [6], carbon fibers [7] or surfactants [8-10], after which the support is removed by calcination. The second is the (partial) 'zeolitization' of the walls of a mesoporous aluminosilicate, e.g. Al-MCM-41 [11], or a macroporous oxide like diatom [4]. In the third method, which was developed recently by researchers from Haldor Topsøe, the mesopores are templated with carbon during the zeolite synthesis. It consists of impregnating a carbon source, e.g. carbon black $[12,13]$ or carbon nanotubes [14], with a zeolite precursor solution after which the material is subjected to a hydrothermal treatment in order to grow the zeolite crystals. During the subsequent calcination the carbon is burned away, resulting in intracrystalline mesopores in the zeolite. Earlier, layers of zeolites have been grown on hollow carbon fibers $[7,15,16]$. Because the diameters of these hollow carbon fibers are in the order of several micrometers, a hollow zeolite tube with intercrystalline meso- and macropores is left after calcination. On the contrary, the method developed by the researchers from Haldor Topsøe results in intracrystalline mesopores. This strategy enables one to tune the size, shape and connectivity of the mesopore system in the zeolite by choosing the proper carbon source and crystallization conditions. It also offers a way to vary the $\mathrm{Si} / \mathrm{Al}$ ratio and the mesopore system independently. This makes it possible to study the individual roles of the mesopore system and the $\mathrm{Si} / \mathrm{Al}$ ratio on the catalytic activity. Up to now mesopores are most often created by steaming and/or acid leaching [17]. However, these post-synthesis treatments also alter the $\mathrm{Si} / \mathrm{Al}$ ratio of the zeolite, making it difficult to separate the contributions of the accessibility, number and nature of the acid sites on the catalytic activity and selectivity.

Here we present an exploratory study on the generation of mesopores by templating with carbon during zeolite synthesis. Next to carbon black we have investigated, for the first time, the potential of carbon nanofibers [18] as template for mesopores. Carbon nanofibers can be produced much cheaper than carbon nanotubes [18] and may bring down the overall synthesis costs. As a model system we have used the synthesis of silicalite-1. The effect of the generated mesopores will be much larger for a zeolite with one-dimensional micropores like mordenite than for a zeolite with a two-dimensional micropore system like silicalite-1. Nonetheless, the beneficial effect of mesopores templated in titanosilicalite- 1 has been demonstrated for the epoxidation of alkenes with hydrogen peroxide [19]. Unlike the synthesis of mordenite, the crystallization of silicalite-1 can be done from a clear solution, which is favorable for an exploratory study of this mesopore templating method. With nitrogen physisorption, scanning electron microscopy and (three-dimensional) transmission electron microscopy (TEM) we have characterized the size and shape of the mesopores and the zeolite crystals to study the influence of the carbon source and zeolite synthesis conditions on the mesopores obtained after burning away the carbon.

\section{Experimental}

\subsection{Nitrogen physisorption}

Nitrogen adsorption and desorption measurements were performed at liquid nitrogen temperature on a Micromeritics ASAP 2400. The samples were outgassed in vacuum at $200{ }^{\circ} \mathrm{C}$ prior to measurement. Micropore volumes and external surface areas were determined using $t$-plot analysis [20]. Pore size distributions were calculated from the desorption isotherm according to the method developed by Barret et al. [21].

\section{2. (3D)-transmission electron microscopy}

For electron microscopy a droplet of a colloidal gold suspension (Sigma, $5 \mathrm{~nm}$ gold) was dried on a copper grid supported carbon film, thus providing markers for the alignment of the data set. The sample was suspended in ethanol using ultrasound after which a droplet of the suspension was dried on this grid. From a representative crystal a tilt series of $\approx 141$ images was taken from about $+70^{\circ}$ to $-70^{\circ}$ with $1^{\circ}$ intervals at a magnification of 14.5 or $19 \mathrm{k}$ on a Tecnai 20 microscope $(200 \mathrm{kV})$, using 
software for automated electron tomography. After alignment of the tilt series a 3D reconstruction of the crystal was calculated as a stack of thin (1-2 nm) slices using IMOD [22].

\subsection{Scanning electron microscopy}

Scanning electron microscopy (SEM) was performed on a Philips XL30 FEG. On the calcined zeolite samples a $10 \mathrm{~nm}$ carbon layer was deposited for conductivity.

\subsection{Materials}

For the synthesis of mesoporous zeolites four types of carbon sources were used. Two carbon black powders (Mogul L and Monarch 1300) with different pore volumes and a pelleted carbon black (BP2000) were obtained from Cabot Corporation. In Table 1 some characteristics of these carbon blacks are given. For the growth of the carbon nanofibers $(\mathrm{CNF})$ a $20 \mathrm{wt} \% \mathrm{Ni} / \mathrm{SiO}_{2}$ catalyst was prepared by homogeneous deposition-precipitation using the hydrolysis of urea [23]. Prior to the fiber growth the Ni-catalyst was reduced in situ for $2 \mathrm{~h}$ in a flow of $20 \% \mathrm{H}_{2} / \mathrm{Ar}(1 \mathrm{bar})$ at $700{ }^{\circ} \mathrm{C}$. Next the $\mathrm{CNF}$ s were grown at $550{ }^{\circ} \mathrm{C}$ in $\mathrm{CO} / \mathrm{H}_{2} / \mathrm{Ar}(20 /$ $7 / 73$ ) at 1 bar total pressure for $24 \mathrm{~h}$. Subsequently the CNFs were refluxed for $3 \mathrm{~h}$ in a $1 \mathrm{M}$ solution of $\mathrm{NaOH}$ (Merck p.a.) in water to remove the silica support. After filtration and washing the CNFs were refluxed for $1 \mathrm{~h}$ in a 1:1 mixture of concentrated $\mathrm{HNO}_{3}$ (Lamers \& Pleuger 65\%, pure) and $\mathrm{H}_{2} \mathrm{SO}_{4}$ (Merck, 95-97\% p.a.) to remove the nickel and to activate the CNFs by forming oxygen containing groups [24]. After filtration and washing (until $\mathrm{pH} \sim 7$ ) the $\mathrm{CNFs}$ were dried at $60{ }^{\circ} \mathrm{C}$. The amounts of chemicals used for the synthesis of the samples are given in Table 2. In a typical synthesis $2.5 \mathrm{~g}$ of a carbon source in a porcelain cup was impregnated to incipient wetness with a solution of tetrapropylammonium hydroxide (TPAOH: Alfa, 40\% aqueous solution), water and ethanol. The amount of ethanol corresponded to half of the carbon pore volume (determined with a 50:50 water:ethanol mixture). After evaporation of the ethanol the carbon was impregnated with tetraethylorthosilicate (TEOS: Acros $98 \%$ ) to $\approx 20 \%$ excess compared to incipient wetness, resulting in an overall molar composition of about TPAOH: $\mathrm{H}_{2} \mathrm{O}: \mathrm{TEOS}=1: 20: 2.4$. After ageing for $3 \mathrm{~h}$ the porcelain cup was placed in an autoclave, while enough water was added around the porcelain cup to produce saturated steam. The autoclave was heated to $170{ }^{\circ} \mathrm{C}$ either with $0.5^{\circ} \mathrm{C} /$ min or by rapidly heating it in an oven to the final temperature. After 3 days the autoclave was cooled to room temperature, after which the product was filtered and washed three times with water. Finally the product was dried at $60{ }^{\circ} \mathrm{C}$. The template and carbon source were removed by calcination in air according to the following scheme: heating to $120^{\circ} \mathrm{C}$ with $5^{\circ} \mathrm{C} / \mathrm{min}$, after $1 \mathrm{~h}$ heated to $300{ }^{\circ} \mathrm{C}$ with $2{ }^{\circ} \mathrm{C} / \mathrm{min}$ (to remove the TPA), after $3 \mathrm{~h}$ heated to $600{ }^{\circ} \mathrm{C}$ with $5^{\circ} \mathrm{C} / \mathrm{min}$ (to remove the carbon) and after $8 \mathrm{~h}$ cooled to room

Table 1

Physical data of the carbon sources used

\begin{tabular}{ccllllll}
\hline & $\begin{array}{l}\text { BET SA } \\
\left(\mathrm{m}^{2} / \mathrm{g}\right)\end{array}$ & $\begin{array}{l}\mathrm{N}_{2} \text { pore } \\
\text { volume }(\mathrm{ml} / \mathrm{g})\end{array}$ & $\begin{array}{l}\text { Median pore } \\
\text { diameter }(\mathrm{nm})^{\mathrm{a}}\end{array}$ & $\begin{array}{l}\text { Primary } \\
\text { particle size }(\mathrm{nm})\end{array}$ & $\begin{array}{l}\text { DBPA } \\
(\mathrm{ml} / 100 \mathrm{~g})^{\mathrm{b}}\end{array}$ & $\begin{array}{l}\text { Bulk density } \\
(\mathrm{g} / \mathrm{ml})\end{array}$ & $\begin{array}{l}\text { Volatile } \\
\text { content } \% 0^{\mathrm{c}}\end{array}$ \\
\hline $\begin{array}{l}\text { Mogul L } \\
\text { Monarch- }\end{array}$ & 129 & 0.84 & 30 & $24^{\mathrm{d}}$ & $62^{\mathrm{d}}$ & $0.24^{\mathrm{d}}$ & $9.0^{\mathrm{d}}$ \\
1300 & 485 & 0.94 & 10 & $13^{\mathrm{d}}$ & & $0.26^{\mathrm{d}}$ & $5.0^{\mathrm{d}}$ \\
BP2000 & $1500^{\mathrm{d}}$ & & & & $330^{\mathrm{d}}$ & $0.15^{\mathrm{d}}$ & $2.0^{\mathrm{d}}$ \\
CNF & 154 & 0.25 & 8 & $12^{\mathrm{d}}$ & & 0.72 & $7.0^{\mathrm{f}}$ \\
\hline
\end{tabular}

${ }^{a}$ From BJH method of desorption isotherm.

${ }^{b}$ Di-butyl phtalate adsorption; a higher DBPA indicates a stronger agglomeration of the primary particles.

${ }^{\mathrm{c}}$ By heating to $950{ }^{\circ} \mathrm{C}$; measure for amount of oxygen containing groups.

${ }^{\mathrm{d}}$ Data from Cabot Corporation [33].

${ }^{\mathrm{e}}$ Fiber diameter.

${ }^{\mathrm{f}}$ Estimate from [24] (heated to $850^{\circ} \mathrm{C}$ ). 
Table 2

Amounts of chemicals used for the synthesis of mesoporous zeolites

\begin{tabular}{llllllll}
\hline & $\begin{array}{l}\text { Carbon } \\
(\mathrm{g})\end{array}$ & $\begin{array}{l}\text { Water } \\
(\mathrm{ml})\end{array}$ & $\begin{array}{l}\text { TPAOH } \\
40 \%(\mathrm{ml})\end{array}$ & $\begin{array}{l}\text { Ethanol } \\
(\mathrm{ml})\end{array}$ & $\begin{array}{l}\text { TEOS } \\
(\mathrm{g})\end{array}$ & $\begin{array}{l}\mathrm{NaAlO}_{2} \\
(\mathrm{~g})\end{array}$ & $\begin{array}{l}\mathrm{NaOH} \\
(\mathrm{g})\end{array}$ \\
\hline SIL-SiO $_{2}$ & 2.5 & 3.90 & $0.19^{\mathrm{b}}$ & & $0.33^{\mathrm{c}}$ & 0.074 \\
SIL-Mogul & 2.5 & 0.25 & 1.25 & 1 & 1.21 & \\
SIL-Monarch & 2.5 & 0.5 & 2.5 & 2 & 2.42 & \\
SIL-CNF & 2.5 & & 1.25 & 1.25 & 1.15 & \\
ZSM-Monarch & 2.5 & & 2.25 & 2.25 & 2.33 & 0.02 \\
SIL-HT & 15 & 3.3 & 22.2 & 23.75 & 25.0 & & \\
\hline
\end{tabular}

${ }^{\text {a }}$ Type of carbon is described in Table 3.

${ }^{\mathrm{b}} \mathrm{TPABr}(\mathrm{g})$.

${ }^{\mathrm{c}}$ Aerosil 200.

temperature. These silicalite-1 samples will be indicated corresponding to the carbon source used as SIL-Mogul, SIL-Monarch and SIL-CNF. Yields are between 0.13 and $0.26 \mathrm{~g}$ of zeolite per gram of carbon used.

SIL-HT was synthesized at Haldor Topsøe as follows: $15 \mathrm{~g}$ of carbon black (BP2000) was dried in an oven at $130{ }^{\circ} \mathrm{C}$ for $2 \mathrm{~h}$. The cooled carbon black was impregnated to incipient wetness with a clear solution consisting of $22.2 \mathrm{~g}$ of a $40 \mathrm{wt} \%$ aqueous solution of tetrapropylammonium hydroxide, $3.3 \mathrm{~g}$ of water and $19.0 \mathrm{~g}$ of $99 \%$ ethanol. Subsequently, the ethanol was evaporated at room temperature and the carbon black was then impregnated to incipient wetness with $25.0 \mathrm{~g}$ of tetraethylorthosilicate (TEOS). Over night, i.e. at least $16 \mathrm{~h}$, the resulting sample was allowed to digest and then the sample was crystallized in an autoclave at $180{ }^{\circ} \mathrm{C}$ for $72 \mathrm{~h}$ (with an estimated heating rate of $2^{\circ} \mathrm{C} / \mathrm{min}$ ). The resulting sample was then slurried in water, filtered, dried at $120^{\circ} \mathrm{C}$ and then calcined in a muffle furnace by distributing the sample in a thin layer $(\approx 2-3 \mathrm{~mm})$, ramping the temperature with $1{ }^{\circ} \mathrm{C} / \mathrm{min}$ to $550{ }^{\circ} \mathrm{C}$ and stay at this temperature for $6 \mathrm{~h}$.

Two samples were prepared under different conditions. For one sample $\mathrm{SiO}_{2}$ (Degussa aerosil 200) dissolved in a $\mathrm{NaOH}$ solution was used as a silicon source instead of TEOS and TPABr was used instead of TPAOH. The overall molar composition of the viscous gel was $\mathrm{NaOH}: \mathrm{TPABr}$ : $\mathrm{SiO}_{2}: \mathrm{H}_{2} \mathrm{O}=2.6: 1: 7.7: 303$. In order to "impregnate" this gel the carbon black (Mogul L) was introduced by stirring with a spatula. After $3 \mathrm{~h}$ of ageing the autoclave was directly placed in an oven at $150{ }^{\circ} \mathrm{C}$ for 3 days. This sample will be indicated as $\mathrm{SIL}-\mathrm{SiO}_{2}$. For the other sample (with different synthesis conditions) a source of aluminum was added. The carbon source (Monarch 1300) was impregnated with a solution of TPAOH, sodium aluminate (Riedel de Haen, technical, anhydrous) and ethanol. After evaporation of the ethanol the material was impregnated with TEOS $(20 \%$ excess compared to incipient wetness). The overall molar synthesis composition was TPAOH: $\mathrm{H}_{2} \mathrm{O}: \mathrm{Na}-$ $\mathrm{AlO}_{2}:$ TEOS $=1: 17: 0.056: 2.5$, leading to a theoretical $\mathrm{Si} / \mathrm{Al}$ ratio of 45 . After ageing for $3 \mathrm{~h}$ the autoclave was heated to $180{ }^{\circ} \mathrm{C}$ with $0.5^{\circ} \mathrm{C} / \mathrm{min}$ and kept at that temperature for 3 days. This mesoporous ZSM-5 sample will be denoted as ZSM-Monarch. An overview of the samples and the synthesis conditions is given in Table 3 in Section 3.

\section{Results}

\subsection{Nitrogen physisorption}

In Fig. 1 the nitrogen adsorption and desorption isotherms of the zeolites after burning off the carbon are given. The isotherms of all samples contain a hysteresis loop at relative pressures higher than $p / p_{0}=0.4$. All these hysteresis loops have an upward curvature at relative pressures above 0.8 . This upward curvature indicates the presence of cylindrical mesopores. For SIL-Mogul, SIL-SiO SIL-Monarch and SIL-CNF the hysteresis loop 
Table 3

Synthesis conditions and nitrogen adsorption data of the six mesoporous zeolite samples

\begin{tabular}{|c|c|c|c|c|c|c|}
\hline & $\mathrm{C}$-source ${ }^{\mathrm{a}}$ & Si-source & $\begin{array}{l}T\left({ }^{\circ} \mathrm{C}\right) / \mathrm{ramp} \\
\left({ }^{\circ} \mathrm{C} / \mathrm{min}\right)\end{array}$ & $\begin{array}{l}V_{\text {micro }} \\
(\mathrm{ml} / \mathrm{g})^{\mathrm{b}}\end{array}$ & $\begin{array}{l}V_{\text {meso+macro }} \\
(\mathrm{ml} / \mathrm{g})^{\mathrm{c}}\end{array}$ & $\begin{array}{l}\text { Ext. SA } \\
\left(\mathrm{m}^{2} / \mathrm{g}\right)^{\mathrm{d}}\end{array}$ \\
\hline SIL-HT & BP2000 & TEOS & $180 / 2$ & 0.13 & 0.42 & 91 \\
\hline SIL-SiO ${ }_{2}$ & Mogul & $\mathrm{SiO}_{2}{ }^{\mathrm{e}}$ & $150 /$ & 0.13 & 0.05 & 9 \\
\hline SIL-CNF & CNF & TEOS & $170 / 0.5$ & 0.11 & 0.26 & 72 \\
\hline SIL-Mogul & Mogul & TEOS & $170 /$ & 0.14 & 0.14 & 25 \\
\hline SIL-Monarch & Monarch & TEOS & $170 /$ & 0.14 & 0.11 & 20 \\
\hline ZSM-Monarch & Monarch & TEOS & $180 / 0.5$ & 0.13 & 0.71 & 105 \\
\hline
\end{tabular}

${ }^{a} \mathrm{CNF}=$ carbon nanofiber, Mogul = Mogul L, Monarch = Monarch 1300, BP2000 = Black Pearls 2000: carbon black pellets.

${ }^{\mathrm{b}}$ From $t$-plot with density of solid nitrogen ( $V_{2}$ in Fig. 9), see Section 4.

${ }^{\mathrm{c}} V_{\text {total }}-V_{\text {micro }}$.

${ }^{\mathrm{d}}$ From $t$-plot, sum of external surface area and mesopore surface area.

e Aerosil 200.
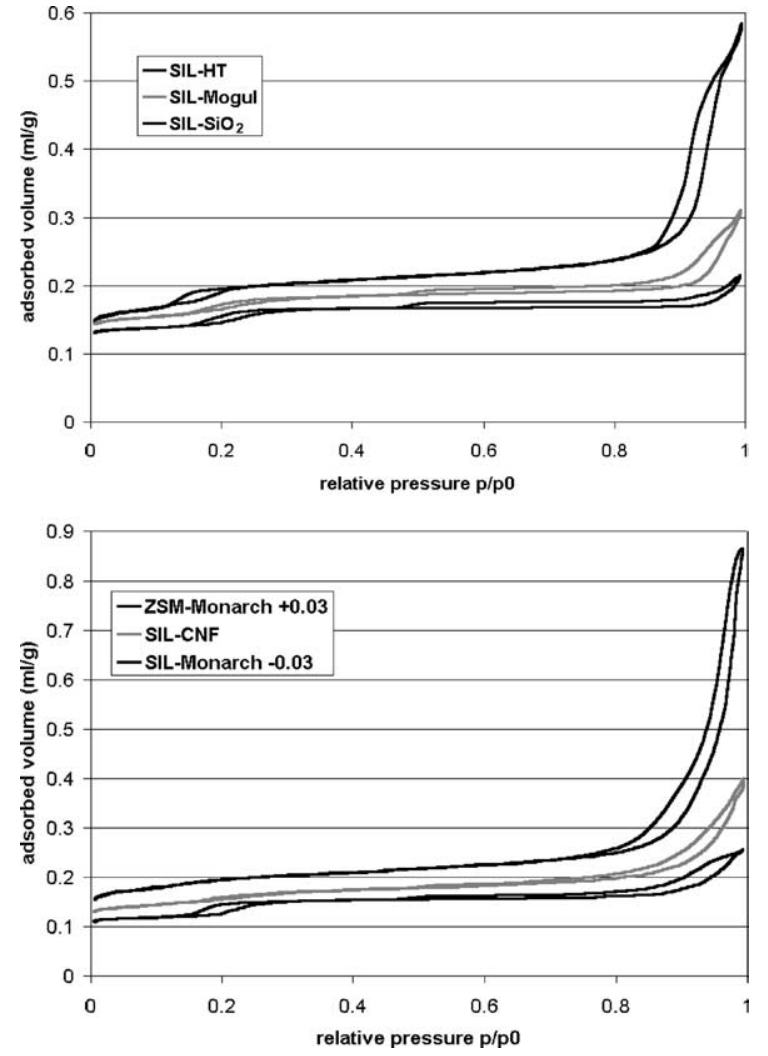

Fig. 1. Nitrogen adsorption and desorption isotherms of mesoporous zeolites. The order of the legend is the order of the isotherms. Two isotherms in the lower image have been shifted by $0.03 \mathrm{ml} / \mathrm{g}$ for clarity.

has a flat part between relative pressures of 0.4 and 0.8 . This indicates the presence of a limited number of inkbottle mesopores. All isotherms, except for the isotherm of ZSM-Monarch, contain a second hysteresis loop at a relative pressure of about 0.2 . For SIL-CNF this second hysteresis loop is small and hardly visible in Fig. 1. In Table 3 the external surface areas and micro- and mesopore volumes of all six samples are given. The micropore volumes given are calculated with the $t$-plot method and correspond to the second plateau in the isotherm (after the first hysteresis loop). Because it is hard to separate the intercrystalline mesopore volume from the intracrystalline mesopore volume the sum of both volumes is given. In Fig. 2 the pore size distributions of the mesoporous zeolites after calcination are given. The pore size distributions are cut off to exclude two peaks at $\approx 2$ and $4 \mathrm{~nm}$, which are artifacts of the BJH method due to the closing of the two hysteresis loops. All pore size distributions are broad ( 6 to $>50 \mathrm{~nm}$ ) with a median size between 15 and $30 \mathrm{~nm}$.

\subsection{Electron microscopy}

In Fig. 3 a series of electron microscopy images of $\mathrm{SIL}-\mathrm{SiO}_{2}$ are given as obtained with SEM and transmission electron microscopy. The backscattered electron (BE) image at low magnification in Fig. 3a shows many large zeolite particles (white shapes) sticking out of an amorphous carbon agglomerate. In Fig. 3b a secondary electron (SE) image of one of these zeolite crystals is shown. From this image it is clear that there is partial 

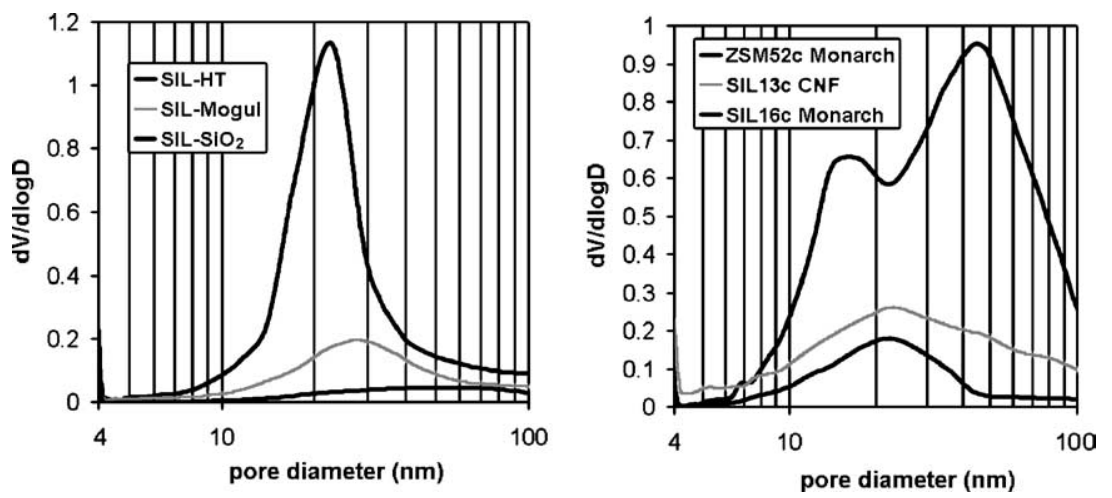

Fig. 2. Pore size distributions of mesoporous zeolites. The order of the legend is the order of the isotherms.

contact between the carbon and the zeolite crystal. The SE image in Fig. 3c gives a closer look at the interface between the carbon and the zeolite particle. The unstructured material on top of the zeolite crystal could well be some carbon, which might indicate that this carbon extends inside the zeolite crystal. In Fig. 3d a SE image is given which shows the zeolite crystals after the carbon has been burned away. The surfaces of the crystals seem to be rather smooth. Fig. 3e shows a TEM image of a zeolite crystal after the carbon has been removed. From this image it is clear that the crystals are too thick to image the mesopores with (3D)-TEM. The lengths of the zeolite crystals are about $15 \mu \mathrm{m}$ and rather uniform.

Fig. 4 shows a series of SEM and (3D)-TEM images of SIL-Mogul. From the BE image in Fig. 4a it can be seen that the zeolite crystals are between $\approx 0.5$ and $2.5 \mu \mathrm{m}$ in size and that many are located at the surface of the carbon agglomerates. Some of these zeolite crystals are shown in the SE images of Fig. $4 \mathrm{~b}$ and c. The crystals in Fig. 4b seem to be separated from the carbon, whereas the crystal in Fig. 4c has most likely grown around some carbon as it has grown inside the pores in the carbon agglomerate. In Fig. 4d an SE image of a zeolite crystal after burning off the carbon matrix is shown. The surface of the crystals shows appreciable roughness that can be indicative of mesoporosity [25-27] as well as a big hole in the side of one of the crystals. The size of this big hole is of the same order of magnitude as the mesopores shown in the (3D)-TEM slice in Fig. 4f, whereas the roughness of the surface seems to consist of much smaller features. The TEM image in Fig. 4e shows a zeolite crystal with many light areas, caused by the presence of mesopores. One of the slices through the $3 \mathrm{D}$ reconstruction of this crystal is shown in Fig. 4f. The mesopores inside the zeolite crystal are clearly visible as lighter areas. There are several places where the mesopores reach the external surface of the zeolite crystal. Already from this single image it can also be seen that the mesopores are highly branched. From the study of subsequent slices it is clear that the majority of the mesopores are connected to form a network. Besides crystals with such a mesopore network also (larger) crystals are present which do not show any mesopores, or which are too thick to draw conclusions about the presence of mesopores from TEM imaging. These larger crystals show the characteristic shape of the crystals in Fig. 4b, whereas the crystals that do contain mesopores show multiple faces, just like the one in Fig. 4e.

Fig. 5 shows a series of SEM and (3D)-TEM images of SIL-Monarch. The BE image in Fig. 5a shows that the zeolite crystals are largely separated from the carbon agglomerates. The size of the crystals is between 1 and $4 \mu \mathrm{m}$. In Fig. $5 \mathrm{~b}$ an SE image is given, which shows that there is contact between the zeolite crystal and the carbon, although the zeolite has grown out of the carbon matrix. After the carbon has been burned away, the zeolite crystals show smooth surfaces in the SE image (Fig. 5c). Most of the crystals are too thick to image any mesopores with TEM. In Fig. 5d a 

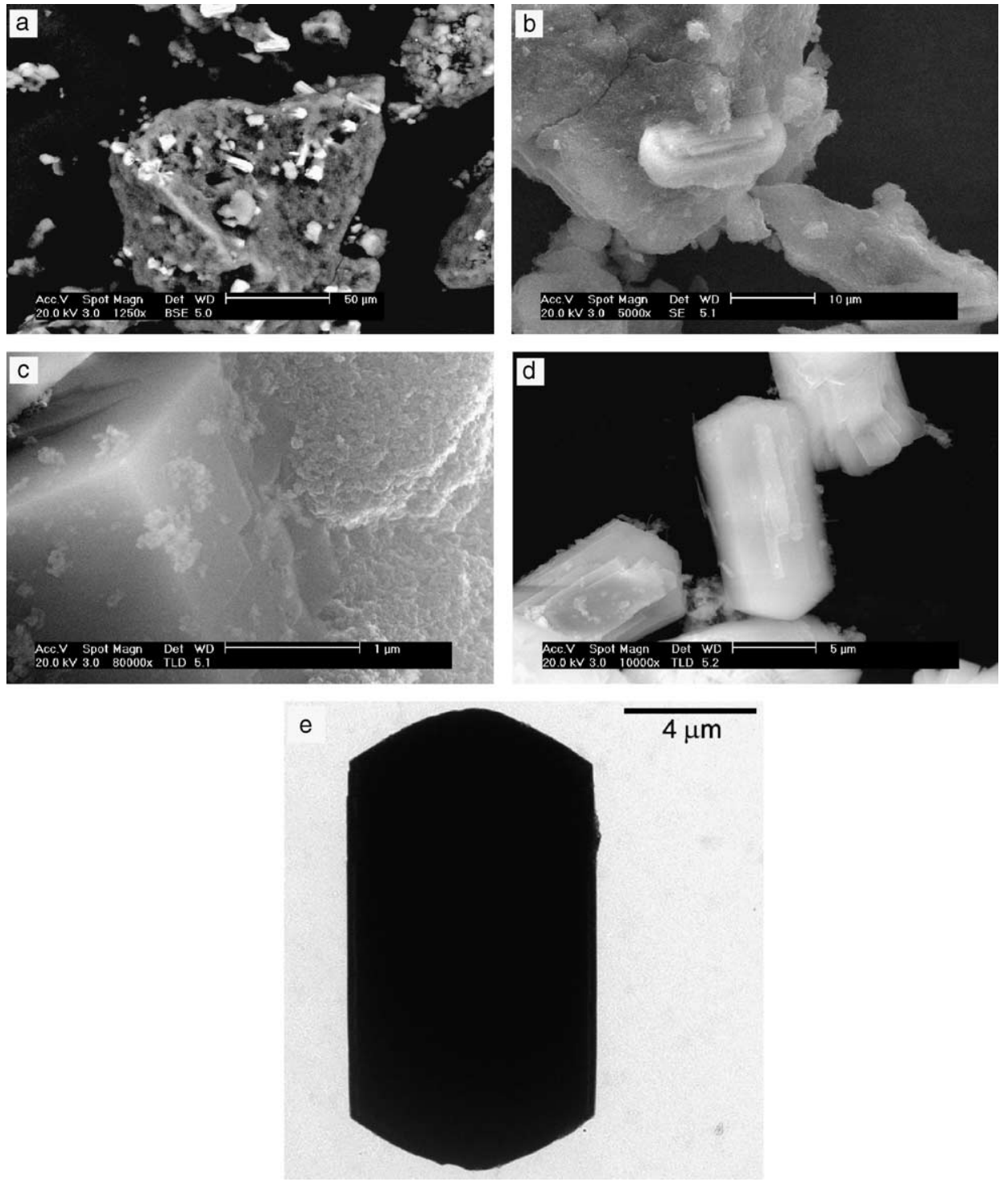

Fig. 3. Electron microscopy of $\mathrm{SIL}_{-} \mathrm{SiO}_{2}$ with the carbon matrix present $(\mathrm{a}-\mathrm{c})$ and after burning off the carbon matrix $(\mathrm{d}$, e): (a) backscattered electrons image (SEM), (b-d) secondary electrons images (SEM), (e) TEM image.

TEM image of one of the thinnest crystals is shown. In this image the mesopores inside the crystal can be seen as light areas. In Fig. 5e a slice through the $3 \mathrm{D}$ reconstruction of the zeolite crystal of Fig. 5d also shows the mesopores. Next to the zeolite crystal and the mesopores also some unstructured material, probably remains of the carbon matrix, are visible. From the study of subsequent slices through the reconstruction it seems that there are connections between some of the mesopores, but only few openings to the external surface were found.

Fig. 6 shows a series of SEM and (3D)-TEM images of ZSM-Monarch. The BE image in Fig. 6a shows many small zeolite crystals in a carbon particle. Besides zeolite crystals outside the carbon 

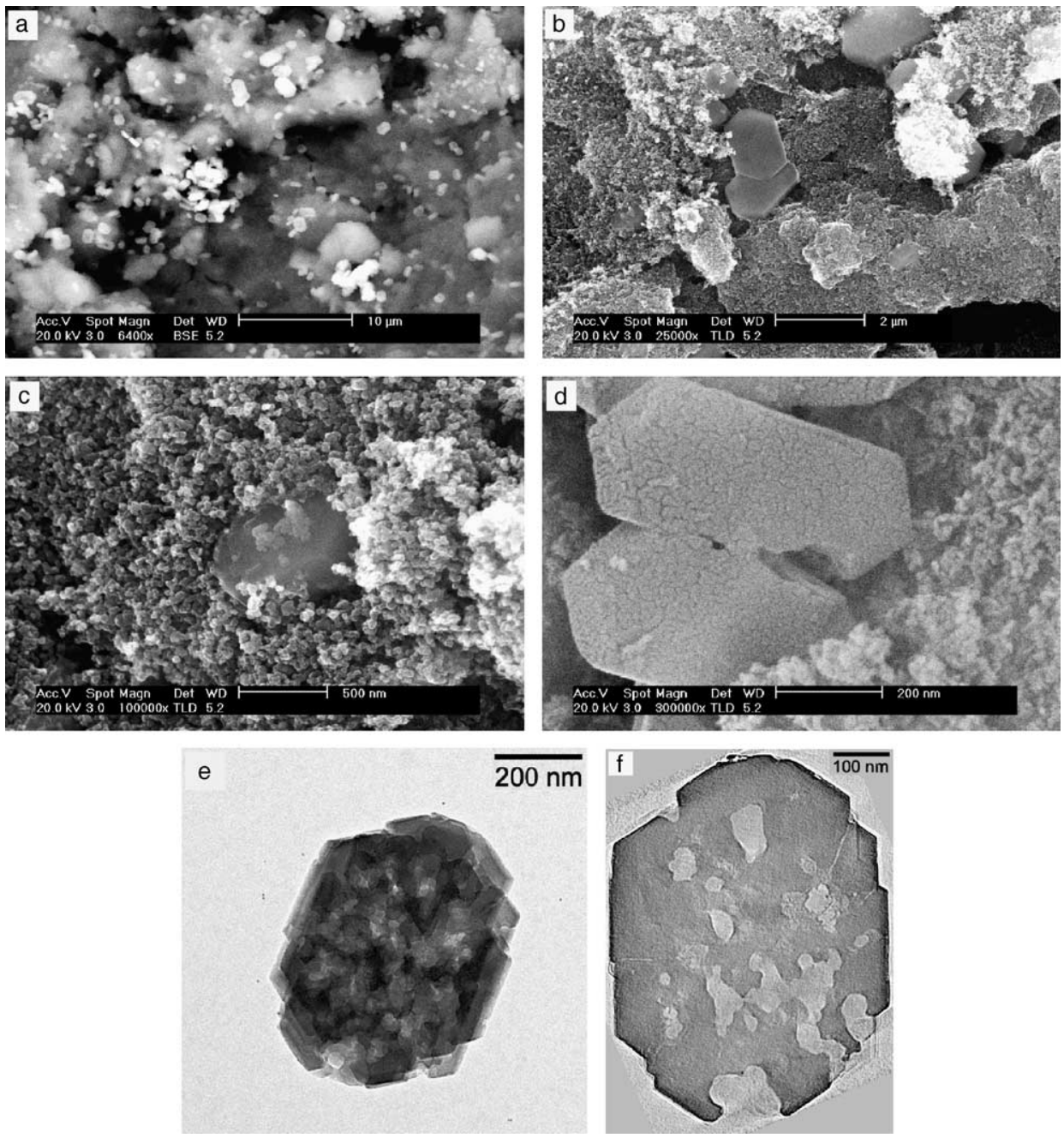

Fig. 4. Electron microscopy of SIL-Mogul with the carbon matrix present (a-c) and after burning off the carbon matrix (d-f): (a) backscattered electrons image (SEM), (b-d) secondary electrons images (SEM), (e) TEM image, (f) (3D)-TEM slice.

particle that show up bright white, there are a few bright white spots visible in the area of the carbon particle, whereas the majority of the zeolite crystals is more vaguely visible. Fig. $6 \mathrm{~b}$ shows an SE image of a zeolite crystal that caused a bright white spot in Fig. 6a in the area of the carbon particle. This crystal sticks out of the surface of the carbon matrix. A zeolite crystal that is more vaguely visible in Fig. 6a is present below the surface of the carbon matrix and is hardly visible in the SE image of Fig. 6c. After burning off the carbon very dif- ferent zeolite crystals are obtained, as can be seen from the SE images in Fig. 6d and e and from the TEM images in Fig. 6f and $g$. The size of the crystals is between $\approx 1$ and $6 \mu \mathrm{m}$. The larger zeolite crystals have a smooth surface, while the surface of the smaller crystals is more rough. The TEM image in Fig. 6g shows a particle with mesopores, but most of the zeolite crystals are too thick to image possible mesopores. Besides the zeolite crystals also amorphous material is present after the carbon has been burned away. 

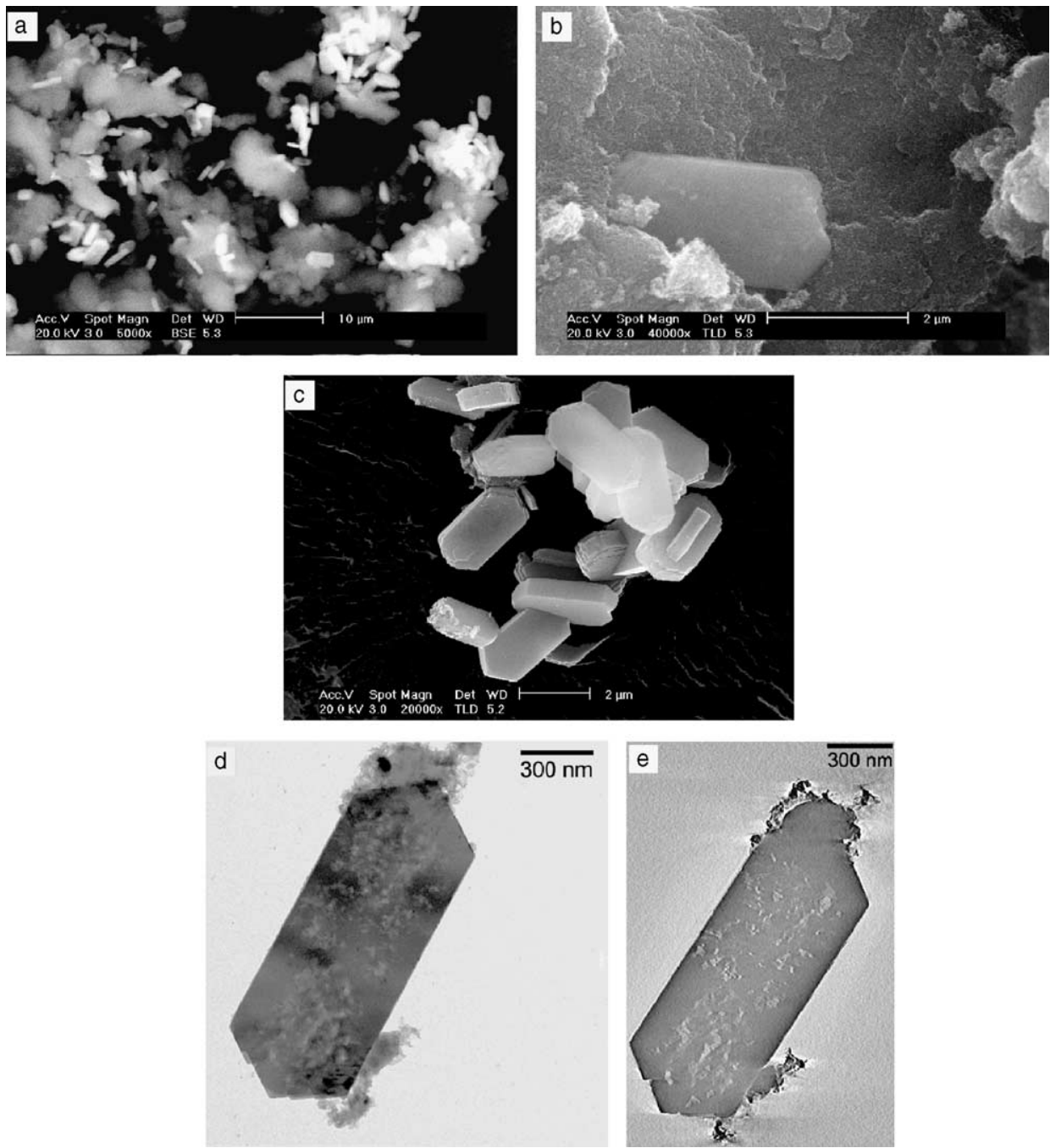

Fig. 5. Electron microscopy of SIL-Monarch with the carbon matrix present $(\mathrm{a}, \mathrm{b})$ and after burning off the carbon matrix (c-e): (a) backscattered electrons image (SEM), (b, c) secondary electrons images (SEM), (d) TEM image, (e) (3D)-TEM slice.

In Fig. 7 a series of SEM and (3D)-TEM images of SIL-HT is given. This material was only characterized after the carbon had been burned away. The SE images in Fig. $7 \mathrm{a}$ and $\mathrm{b}$ and the TEM image in Fig. 7c show cauliflower like zeolite crystals. The crystal size is rather uniform and ranges from $\approx 0.6$ to $1 \mu \mathrm{m}$. A slice through the $3 \mathrm{D}$ reconstruction of the zeolite crystal in Fig. $7 \mathrm{c}$ is given in Fig. 7d. It clearly shows that the high mesoporosity of this material is due to the inter- connected mesopore system that starts at the external surface of the crystals.

In Fig. 8 a series of SEM and (3D)-TEM images of SIL-CNF is given. From the SE images in Fig. $8 \mathrm{a}$ and $\mathrm{b}$ it is clear that the CNFs are strongly interwoven, leading to dense carbon skeins. The zeolite crystals are located on the external surface of the CNF skeins, but there is contact between the carbon and the zeolite crystals. Some CNFs seem to cover up the zeolite crystals, like in Fig. 8c, 

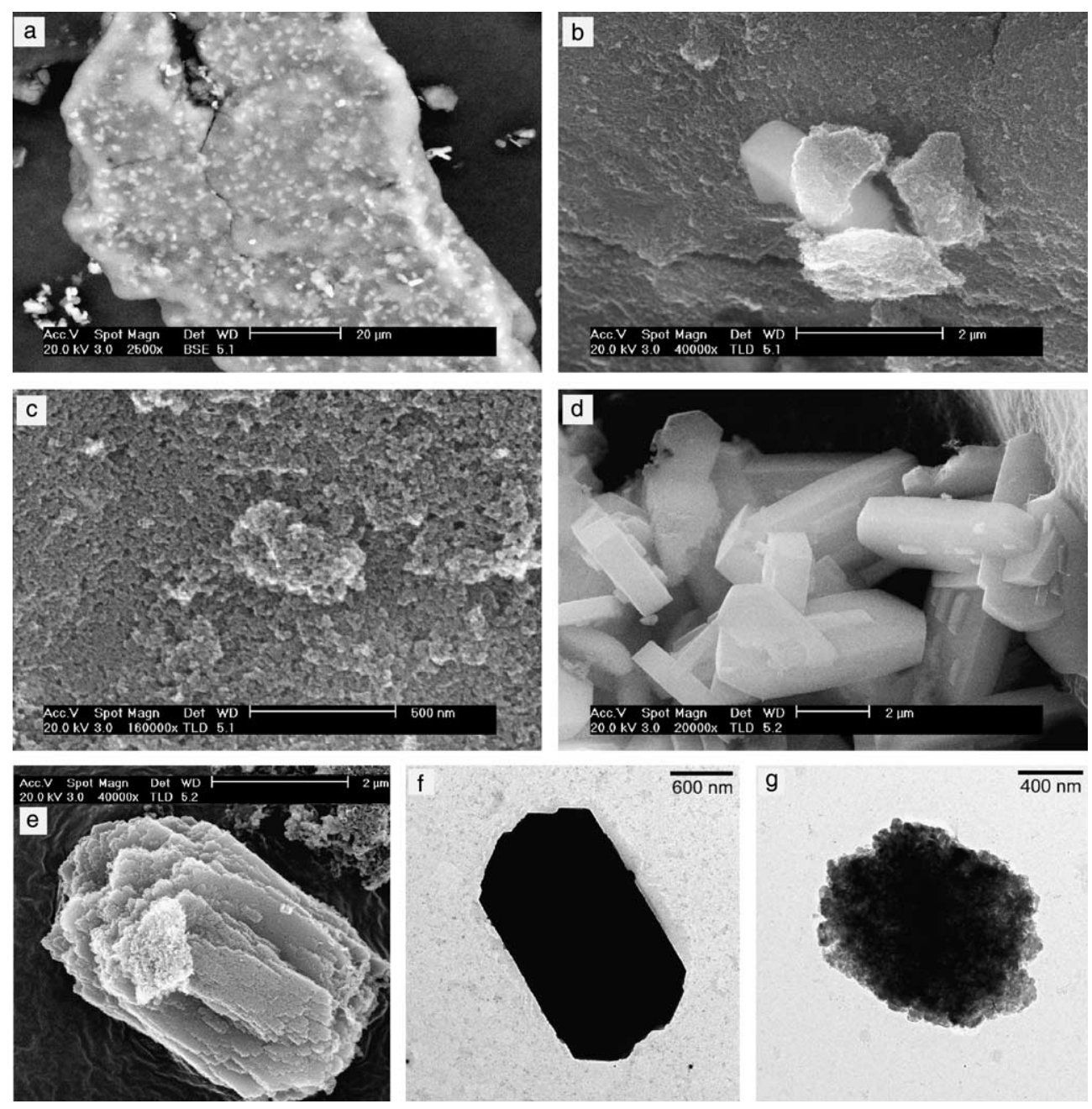

Fig. 6. Electron microscopy of ZSM-Monarch with the carbon matrix present $(\mathrm{a}-\mathrm{c})$ and after burning off the carbon matrix $(\mathrm{d}-\mathrm{g})$ : (a) backscattered electrons image (SEM), (b-e) secondary electrons images (SEM), (f, g) TEM images.

while others seem to extend into the interior of the crystals, as is visible in the middle of Fig. $8 \mathrm{~d}$. The crystals are rather uniform in size, ranging between 0.7 and $1 \mu \mathrm{m}$. The SE images in Fig. 8e-g and the TEM images in Fig. $8 \mathrm{~h}-\mathrm{j}$ show the zeolite crystals after the CNFs have been burned off. In these images the mesopores in the crystals are clearly visible. The SE images show many mesopores that start at the external surface of the crystals. The mesopores vary strongly in diameter. Some have the diameters that equal the diameters of single CNFs $(20-40 \mathrm{~nm})$, e.g. the ones in Fig. $8 \mathrm{~g}$ and $\mathrm{i}$, whereas others have much larger diameters, like in Fig. 8f and j. Fig. 8i shows the left part of the crystal of Fig. 8h at higher magnification. These TEM images clearly show pores running through the zeolite crystals. The crystalline nature of the zeolite particles is apparent from the shape of the crystals. The lattice planes visible in Fig. 8i support this conclusion. In Fig. 8k a slice through the $3 \mathrm{D}$ reconstruction of the SIL-CNF crystal of Fig. $8 \mathrm{j}$ is shown. In this image a mesopore is clearly visible. Subsequent slices show that the large pore in the middle is well connected to the 

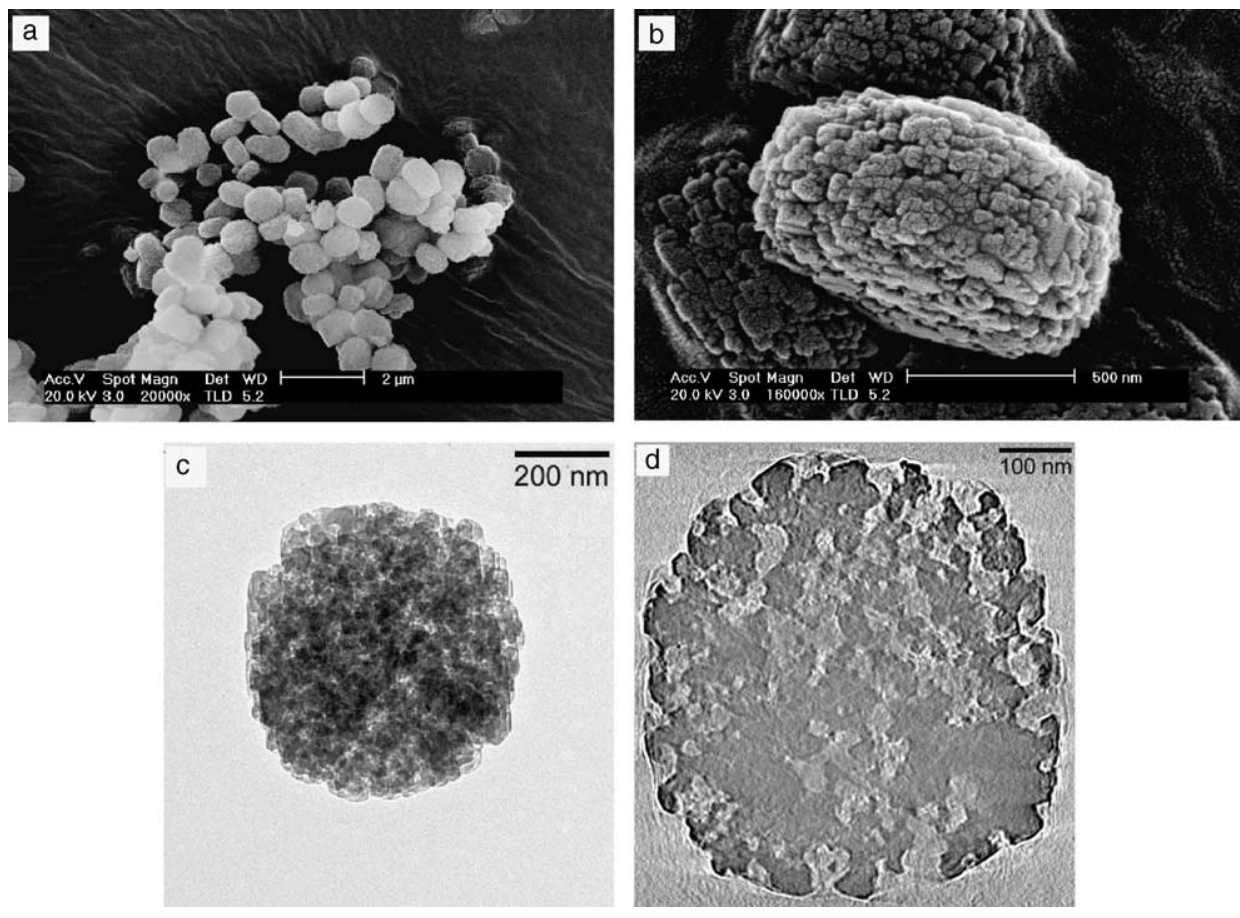

Fig. 7. Electron microscopy of SIL-HT after burning off the carbon matrix: (a, b) secondary electrons images (SEM), (c) TEM image, (d) (3D)-TEM slice.

external surface of the crystal, whereas the small circular mesopore in Fig. 8k (indicated with an arrow) is a cavity inside the crystal. Besides the zeolite crystals also some unstructured material outside the zeolite crystals, probably remains of the carbon matrix, is visible in the TEM images.

\section{Discussion}

\subsection{Micropore volume}

All nitrogen isotherms, except the one of ZSMMonarch, have two hysteresis loops. The hysteresis loop at relative pressures above 0.4 is indicative for mesoporosity. The hysteresis loop at lower relative pressures (around 0.2) is sometimes observed for MFI-type zeolites (like ZSM-5 and silicalite-1) and it becomes more pronounced when the crystal size is increased or when the aluminum content of ZSM-5 is lowered [28-32]. Therefore, it is expected that ZSM-Monarch, the only sample with aluminum in the zeolite framework, does not show this hysteresis loop, while the all-silica zeolites do. This hysteresis loop is due to the fact that the nitrogen can be present in the micropores of MFI in two ways [29]: In the first stage of the adsorption of nitrogen the molecules occupy the energetically most favorable positions in the micropores and intersections. With increasing relative pressure, the molecules reorient themselves to allow the most favorable quadrupole-quadrupole interactions between the nitrogen molecules to occur. In the nitrogen adsorption isotherm this is visible as the sudden adsorption at a relative pressure between roughly 0.1 and 0.2 . The molecules go from a "fluid" phase to a "solid" phase. For the calculation of the micropore volumes the $t$ plot method was used. The adsorbed volume before the steep increase (between a relative pressure of 0.1 and 0.2 in the normal isotherm; $V_{1}$ ) using the density of liquid nitrogen $(0.8081 \mathrm{~g} / \mathrm{ml})$ is in good agreement with the micropore volume calculated using the density of solid nitrogen $(1.026 \mathrm{~g} / \mathrm{ml})$ 

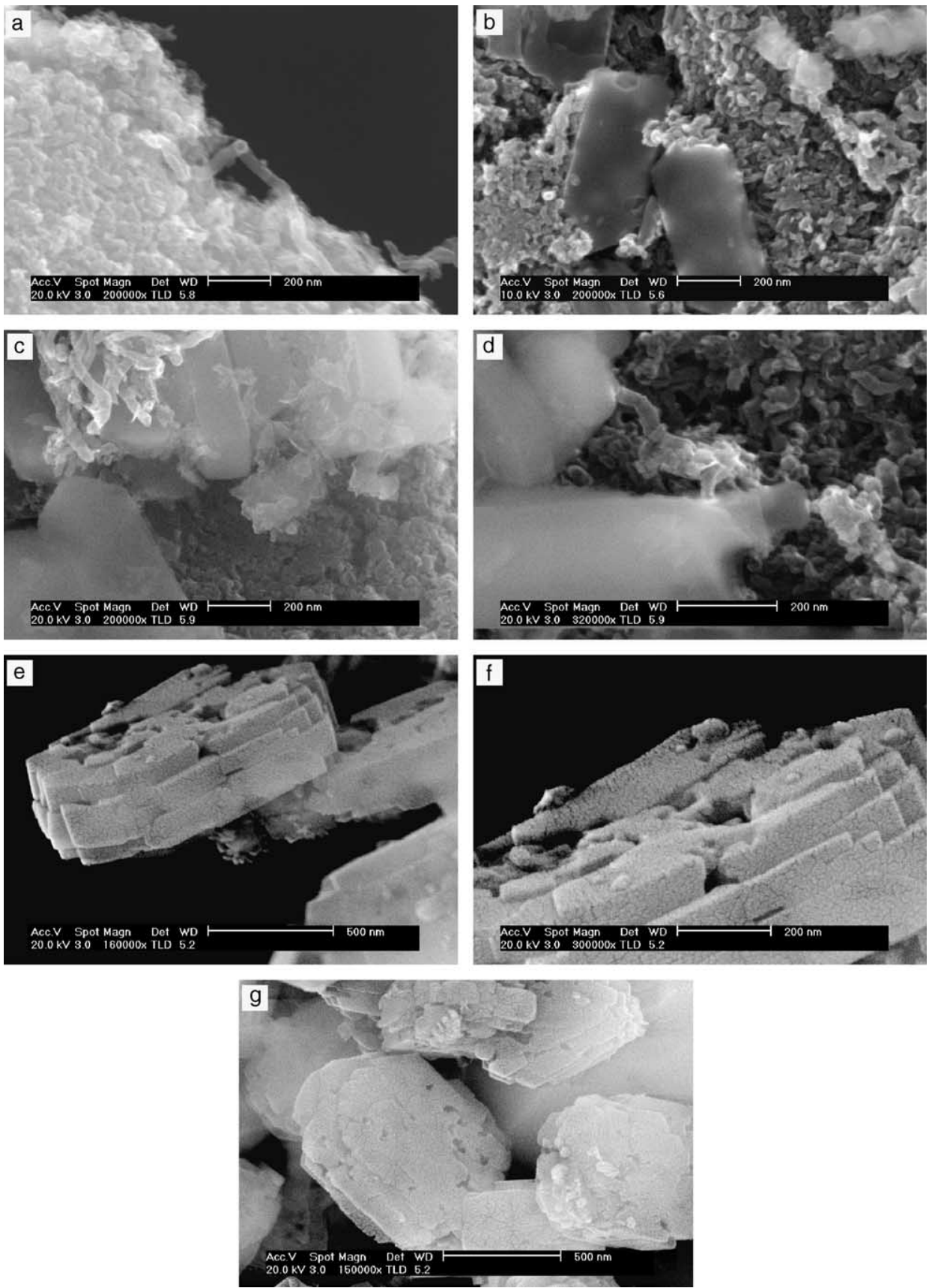

Fig. 8. Electron microscopy of SIL-CNF with the carbon matrix present $(\mathrm{a}-\mathrm{d})$ and after burning off the carbon matrix $(\mathrm{e}-\mathrm{k})$ : (a-g) secondary electrons images (SEM), (h-j) TEM images, (k) (3D)-TEM slice.

from the adsorbed volume including the steep increase $\left(V_{2}\right)$ [28], which is given in Table 3. The calculation of the micropore volume is illustrated in Fig. 9 for $\mathrm{SIL}_{-} \mathrm{SiO}_{2}$. The obtained values of $0.13-0.14 \mathrm{ml} / \mathrm{g}$ are in good agreement with literature data for ZSM-5/silicalite-1 [28]. Only for 


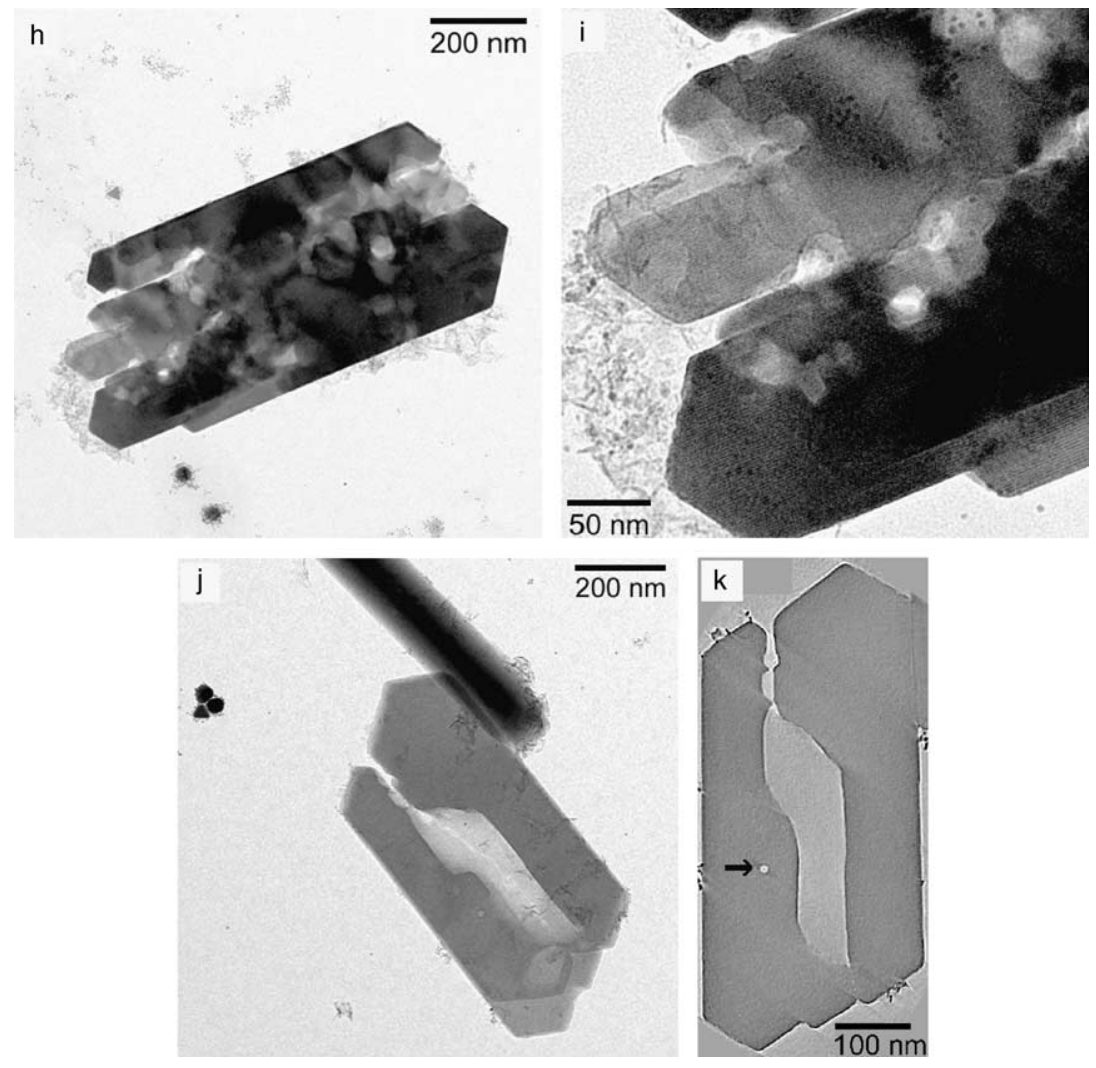

Fig. 8 (continued)

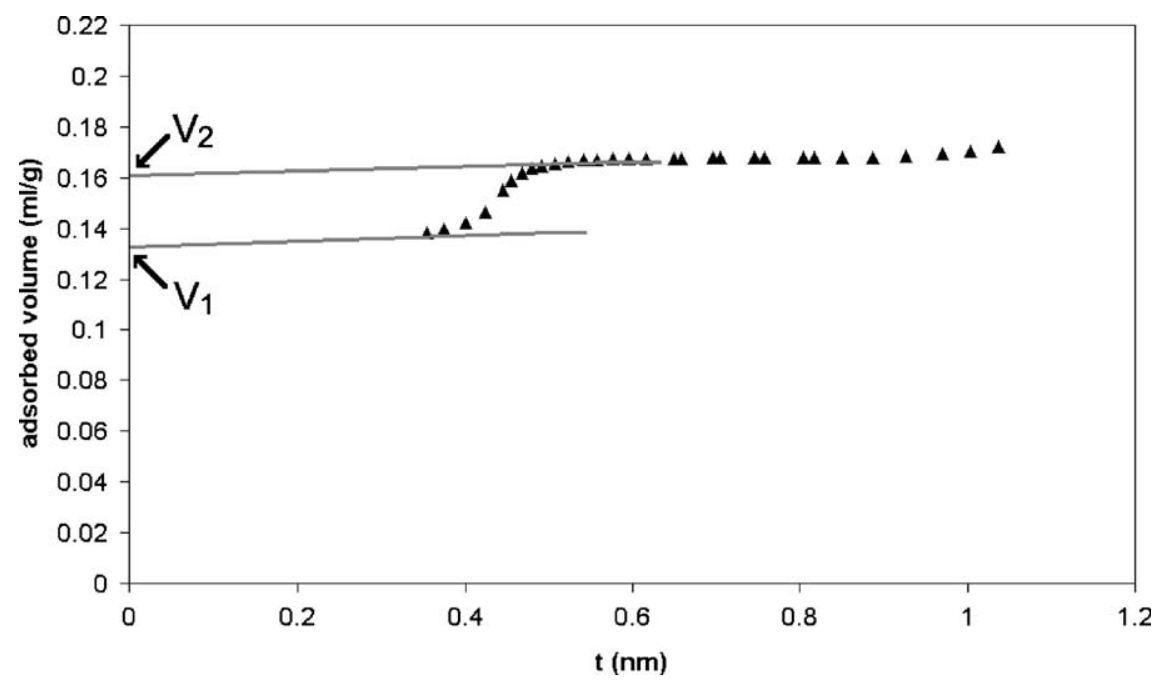

Fig. 9. Micropore volume calculated from $t$-plot for $\mathrm{SIL}-\mathrm{SiO}_{2} . V_{1}=V_{2} * 0.8081 / 1.026$. (see Section 4). 
SIL-CNF the micropore volume is somewhat lower than for the other five samples. Burning off the CNFs was performed at $600{ }^{\circ} \mathrm{C}$, which might be slightly too low to remove all the carbon, as can also be seen from the amorphous material visible in the TEM images in Fig. 8h and i. These remains decrease the micropore volume per gram of material. As SIL-CNF is the only sample that was not synthesized with carbon black, an incomplete removal of the graphitic CNFs (and a complete removal of the carbon blacks) may give an explanation for the fact that only for SIL-CNF the micropore volume is lower than expected.

\subsection{Size and shape of the crystals}

From the very low external and mesopore surface area of SIL-SiO 2 it is evident that this sample consists of very large crystals. This is confirmed by the SEM and TEM measurements, which show crystals of $\approx 15 \mu \mathrm{m}$ length. The large crystal size may have been caused by the relatively low crystallization temperature of $150{ }^{\circ} \mathrm{C}$, but the use of TPABr and $\mathrm{SiO}_{2}$ dissolved in $\mathrm{NaOH}$ instead of TPAOH and TEOS may also have influenced the final size of the crystals. As the silica derived gel was very viscous it had to be stirred through the carbon source with a spatula, probably leading to a low penetration of the solution in the pores of the carbon. Also the condensation of silicon species in the gel is most likely different from the silicon species in the clear solution from TPAOH and TEOS. When the crystals of SIL-SiO ${ }_{2}$ are compared with the crystals of SIL-Mogul there are two main differences. The crystals of SIL-Mogul are much smaller and contain more mesopores than the crystals of SIL-SiO 2 . SIL-Mogul was synthesized from the same carbon source as SIL-SiO ${ }_{2}$ but with TEOS as silicon source and a crystallization temperature of $170{ }^{\circ} \mathrm{C}$. The smaller crystal size of SIL-Mogul can be attributed to the higher crystallization temperature and the increased number of mesopores suggests that the use of TEOS as silicon source favors the penetration in the pores of the carbon matrix. The low crystallization temperature of SIL-SiO 2 seems to be the main reason for the large crystal size, while the low penetration of the synthesis mixture in the carbon agglomerates reduces mesoporosity.
The rough surface and high mesopore volume of SIL-HT correspond to the high external surface area. It has been shown before using electron diffraction that these crystals do not consist of randomly oriented small crystallites that have grown together, but rather of $90^{\circ}$ intergrown crystals (twins) [12]. ZSM-Monarch also has a high mesopore volume and external surface area. Part of this is caused by the cauliflower like crystals shown in Fig. 6g, but also the unstructured porous material found after calcination contributes to this.

The SIL-HT sample has crystals of rather uniform size between 0.6 and $1 \mu \mathrm{m}$. Also SIL-CNF has a very narrow crystal size distribution with crystal sizes in the range of $\approx 0.7-1 \mu \mathrm{m}$. Both samples had been heated to their final temperature (170 and $180^{\circ} \mathrm{C}$, respectively) with a low heating ramp. The two other samples that were heated to a final temperature of $170{ }^{\circ} \mathrm{C}$ (SIL-Mogul and SILMonarch) were rapidly heated in an oven to the final temperature. These two samples show much broader crystal size distributions, viz $0.5-2.5 \mu \mathrm{m}$ for SIL-Mogul and 1-4 $\mu \mathrm{m}$ for SIL-Monarch. Obviously, a low heating ramp gives crystals of more uniform size. However, the ageing time (to hydrolyze the TEOS) could also be of importance. SIL-Mogul and SIL-Monarch were rapidly heated after an ageing time of $3 \mathrm{~h}$. For SIL-HT the heating ramp $\left(2{ }^{\circ} \mathrm{C} / \mathrm{min}\right)$ was higher than the heating ramp of SIL-CNF $\left(0.5^{\circ} \mathrm{C} / \mathrm{min}\right)$, but also the ageing time was longer (16 and $3 \mathrm{~h}$, respectively). So, it could be that the low heating ramps result in smaller crystals because more time is given for the TEOS to hydrolyze before crystallization starts. In order to separate these effects further study is necessary.

Besides a more uniform crystal size distribution, SIL-HT and SIL-CNF also have much higher mesopore volumes than SIL-Mogul and SILMonarch. Most of the large crystals of SIL-Mogul and SIL-Monarch have grown out of the carbon matrix or on top of it, as can be seen from the SEM images of these materials. By growing outside the pores of the carbon agglomerates, the crystals do not grow around carbon any more, thus decreasing the amount of carbon inside the crystals, which leads to a low mesopore volume after the carbon 
has been burned off. SEM imaging indicates that the crystals of SIL-CNF seem to be located mainly on the 'external surface' of the CNF skeins. Because the CNFs are strongly interwoven, they form very dense skeins, making it difficult for the TEOS to penetrate in the carbon matrix and for the zeolite crystals to grow inside the carbon skeins. Therefore, the zeolite crystals can only grow around (clusters of) CNFs sticking out of the surface of the CNF skeins. Nonetheless, SIL-CNF has a much higher mesopore volume than the SIL-Mogul and SIL-Monarch samples. This suggests that CNF skeins are very suitable as secondary templates for mesopores in zeolite synthesis, although the synthesis needs to be optimized.

\subsection{Volume and shape of the mesopores}

CNFs will form only cylindrical mesopores that are connected to the external surface. The length of the CNFs is such that it is unlikely that a nanofiber is completely surrounded by the zeolite crystal, which would lead to inkbottle type mesopores. The SEM images of SIL-CNF indicate that the zeolite crystals grow more or less parallel to the 'surface' of the CNF skeins. This means that these crystals only grow around CNFs that stick out of the 'surface' of the carbon skeins and, consequently, the mesopores start predominantly perpendicular to the zeolite platelets (see Fig. 8e$\mathrm{k}$ ). As the tortuosity of the CNFs is rather low, the cylindrical mesopores templated by the CNFs are rather straight. This is well visible in Fig. $8 \mathrm{~h}$ and $\mathrm{i}$ where straight pores that extend through the platelet are imaged.

Mogul L is a fluffy carbon black with primary particles of $24 \mathrm{~nm}$ and a nitrogen surface area of $129 \mathrm{~m}^{2} / \mathrm{g}$, whereas Monarch 1300 has primary particles of $13 \mathrm{~nm}$ and a nitrogen surface area of $485 \mathrm{~m}^{2} / \mathrm{g}$ [33]. The primary particles of these carbon blacks are aggregated; more so for Monarch 1300 than for Mogul L (see DBPA values in Table 1). The aggregation is such that the mesopores in SIL-Mogul form an interconnected pore system. For SIL-Monarch also interconnected mesopores were found, but due to the size of the zeolite crystals the quality of the (3D)-TEM reconstruction was insufficient to determine whether there are many cavities present and how many openings of the mesopores to the external surface of the zeolite crystal are present. The larger crystals of SILMogul and SIL-Monarch were too thick to allow imaging of the mesopores with (3D)-TEM. However, the larger the zeolite crystal, the higher the chance that a carbon aggregate is completely surrounded by zeolite, leading to inkbottle type of mesopores. The mesopore volume of SIL-Mogul and SIL-Monarch is 3-4 times lower than the mesopore volume of SIL-HT, while all of the samples have been synthesized with a carbon black as carbon source. One reason for this could be that for SIL-Mogul and SIL-Monarch a fluffy powder was used, whereas SIL-HT was synthesized from carbon black pearls. For impregnations, shaped bodies are favored over powders. So, incomplete wetting of the carbon black powders during the impregnation may have had a detrimental effect on the growth of crystals inside the carbon matrix and thereby on the final mesopore volume generated.

For SIL-HT the crystals are relatively small. From the (3D)-TEM reconstruction (Fig. 7d) it is clear that the carbon aggregates have acted as a template for the formation of an interconnected random pore system that extends to the external surface of the zeolite crystals. So, carbon black aggregates can be used as template for cylindrical mesopores, just as CNFs. However, the tortuosity of the mesopores in SIL-HT is much higher than SIL-CNF because the carbon black forms tortuous aggregates of primary particles, while the $\mathrm{CNF}$ are rather straight. A single $\mathrm{CNF}$ has a uniform diameter, which leads to a mesopore without any pore necks. The carbon agglomerates, on the contrary, vary strongly in diameter, which leads to pore necks in the mesopores, as can be seen in Fig. 7d.

\subsection{General remarks}

The mesopore system and crystal size of SIL-HT have been well optimized. The crystals are small, rather uniform in size and have a high mesopore volume. The mesopore system extends throughout the whole particle, leading to a low effective path length for diffusion. The mesopore volume of SIL$\mathrm{CNF}$ is not as high as for SIL-HT (0.26 vs. 0.42 
$\mathrm{ml} / \mathrm{g}$ ); however, the SIL-CNF system is not optimized. As has been indicated above, the CNFs are strongly interwoven which hinders the penetration of the zeolite synthesis solution in the CNF skeins. This leads to mesopores that start perpendicular to the zeolite platelets, while at the same time only a small part of the CNFs is effectively used for templating of the mesopores. For a silicalite- 1 crystal without mesopores the effective path length for diffusion is the thickness of the platelet because of the interconnected micropore system. So, straight mesopores that start perpendicular to the platelet will not be very effective in decreasing the effective path length for diffusion. Therefore, optimization of CNFs as secondary templates for mesopores during synthesis of zeolites should be done on two aspects. The first is to improve the penetration of the synthesis solution in the CNF skeins by using less dense skeins [18] and/or applying vacuum impregnation. With a better use of the carbon also the second aspect, to form more mesopores that run parallel to the platelet, may be improved as the crystals are forced to crystallize around several CNFs that have most likely different orientations. Finally, a better use of the carbon may also result in higher yields of mesoporous zeolite per gram of carbon.

Another area for optimization is the use of different zeolites. As was already mentioned in the introduction, silicalite-1 has been used as a model system. For zeolites with a one-dimensional micropore system the effect of mesopores on the diffusivity is expected to be much larger. However, dedicated synthesis techniques need to be developed for zeolites that grow from a gel or zeolites that need seeds to crystallize. As silicalite-1 crystallizes from a clear solution, the carbon can easily be impregnated with the synthesis solution. If, however, seeds are required for the crystallization, these need to be deposited on the carbon before the synthesis solution is impregnated. If the seeds are impregnated after the synthesis solution, the seeds will stay at the external surface of the carbon agglomerates/skeins and crystallization of the zeolite out of the carbon matrix is expected. For zeolites with higher aluminum contents (lower $\mathrm{Si} /$ $\mathrm{Al}$ ratios) a viscous synthesis gel is obtained rather than a clear solution, making it difficult to im- pregnate this on the carbon. Although the aluminum and silicon source can be impregnated sequentially, it might be difficult to obtain a homogeneous distribution of the silicon and aluminum source through the carbon, which may hinder or prevent crystallization of the desired zeolite.

\section{Conclusions}

Silicalite- 1 crystals have been synthesized in the presence of a carbon matrix. After burning off the carbon mesoporous zeolites were obtained. With dissolved $\mathrm{SiO}_{2}$ at a crystallization temperature of $150{ }^{\circ} \mathrm{C}$ large crystals ( $15 \mu \mathrm{m}$ length) were obtained, whereas the use of TEOS at a crystallization temperature of $170{ }^{\circ} \mathrm{C}$ yielded crystals with a size between 0.5 and $6 \mu \mathrm{m}$, depending on the other synthesis conditions. Low heating rates $\left(0.5{ }^{\circ} \mathrm{C} /\right.$ $\min$ ) to a final crystallization temperature of 170 ${ }^{\circ} \mathrm{C}$ yielded rather uniform small zeolite crystals $(0.6-1 \mu \mathrm{m})$, whereas the crystals were less uniform when the autoclave was rapidly heated to the final temperature, i.e. also crystals up to $6 \mu \mathrm{m}$ were found. Both carbon nanofibers and carbon black aggregates were capable to act as a template for cylindrical mesopores that start at the external surface of the zeolite crystals. However, the tortuosity of the mesopores generated with carbon black was much higher than for the mesopores templated with carbon nanofibers. With increasing zeolite crystal size the chance that carbon aggregates are completely surrounded by the zeolite increases, leading to inkbottle type mesopores. It is concluded that carbon nanofiber skeins are very promising candidates to act as secondary template for the synthesis of mesoporous zeolite crystals. Optimization of the synthesis needs to be done, while there is also a challenge to extend this mesopore templating method to other zeolites.

\section{Acknowledgements}

We thank Rob van Veen, Arend-Jan van Welsenes and Carel van Ballegoy of Shell International Chemicals for help and facilities for the synthesis of the materials, Ad Mens for the nitro- 
gen physisorption measurements and Marjan Versluijs-Helder for the characterization with SEM.

\section{References}

[1] M.E. Davis, Nature 417 (2002) 813.

[2] P. Yang, T. Deng, D. Zhao, P. Feng, D. Pine, B.F. Chmelka, G.M. Whitesides, G.D. Stucky, Science 282 (1998) 2244.

[3] Y. Wang, Y. Tang, A. Dong, X. Wang, N. Ren, W. Shan, Z. Gao, Adv. Mater. 14 (2002) 994.

[4] M.W. Anderson, S.M. Holmes, N. Hanif, C.S. Cundy, Angew. Chem. Int. Ed. 39 (2000) 2707.

[5] J. Sun, Z. Shan, T. Maschmeyer, J.A. Moulijn, M.-O. Coppens, Chem. Commun. (2001) 2670.

[6] L. Huang, Z. Wang, J. Sun, L. Miao, Q. Li, Y. Yan, D. Zhao, J. Am. Chem. Soc. 122 (2000) 3530.

[7] V. Valtchev, B.J. Schoeman, J. Hedlund, S. Mintova, J. Sterte, Zeolites 17 (1996) 408.

[8] A. Karlsson, M. Stoecker, R. Schmidt, Micropor. Mesopor. Mater. 27 (1999) 181.

[9] W. Guo, L. Huang, P. Deng, Z. Xue, Q. Li, Micropor. Mesopor. Mater. 44-45 (2001) 427.

[10] L. Huang, W. Guo, P. Deng, Z. Xue, Q. Li, J. Phys. Chem. B 104 (2000) 2817.

[11] K.R. Kloetstra, H. van Bekkum, J.C. Jansen, Chem. Commun. (1997) 2281.

[12] C.J.H. Jacobsen, C. Madsen, J. Houzvicka, I. Schmidt, A. Carlsson, J. Am. Chem. Soc. 122 (2000) 7116.

[13] A. Carlsson, C. Madsen, I. Schmidt, J. Houzvicka, C.J.H. Jacobsen, European Patent 1106575, 2001.

[14] I. Schmidt, A. Boisen, E. Gustavsson, K. Stahl, S. Pehrson, S. Dahl, A. Carlsson, C.J.H. Jacobsen, Chem. Mater. 13 (2001) 4416.
[15] J. Garcia-Martinez, D. Cazorla-Amoros, A. LinaresSolano, Y.S. Lin, Micropor. Mesopor. Mater. 42 (2001) 255.

[16] S.P.J. Smith, V.M. Linkov, R.D. Sanderson, L.F. Petrik, C.T. O'Connor, K. Keiser, Micropor. Mater. 4 (1995) 385.

[17] S. van Donk, A.H. Janssen, J.H. Bitter, K.P. de Jong, Catal. Rev., in press.

[18] K.P. de Jong, J.W. Geus, Catal. Rev.-Sci. Eng. 42 (2000) 481.

[19] I. Schmidt, A. Krogh, K. Wienberg, A. Carlsson, M. Brorson, C.J.H. Jacobsen, Chem. Commun. (2000) 2157.

[20] B.C. Lippens, B.G. Linsen, J.H. de Boer, J. Catal. 3 (1964) 32.

[21] P. Barret, L.G. Joyner, P.P. Halenda, J. Am. Chem. Soc. 73 (1951) 373.

[22] J.R. Kremer, D.N. Mastronarde, J.R. McIntosh, J. Struct. Biol 116 (1996) 71.

[23] A.J. van Dillen, J.W. Geus, L.A.M. Hermans, J. van der Meijden, J. Proc. Int. Congr. Catal. 6th 2 (1977) 677.

[24] T.G. Ros, A.J. van Dillen, J.W. Geus, D.C. Koningsberger, Chem. Eur. J. 8 (2002) 1151.

[25] M. Ogura, S. Shinomiya, J. Tateno, Y. Nara, M. Nomura, E. Kikuchi, M. Matsukata, Appl. Catal. A 219 (2001) 33.

[26] M. Ogura, S. Shinomiya, J. Tateno, Y. Nara, E. Kikuchi, M. Matsukata, Chem. Lett. (2000) 882.

[27] R. Giudici, H.W. Kouwenhoven, R. Prins, Appl. Catal. A 203 (2000) 101.

[28] P. Voogd, J.J.F. Scholten, H. van Bekkum, Colloids Surf. 55 (1991) 163.

[29] K.S.W. Sing, K.K. Unger, Chem. Ind. 1 (1993) 165.

[30] A. Saito, H.C. Foley, Micropor. Mater. 3 (1995) 543.

[31] B. Sulikowski, J. Klinowski, Appl. Catal. A 84 (1992) 141.

[32] P. Hudec, A. Smieskova, Z. Zidek, L. Sabo, B. Liptakova, Stud. Surf. Sci. Catal. (2001).

[33] Cabot Corporation, European Technical Report S-136, 2000. 